\title{
MARCHA DE ABSORÇÃO DE NUTRIENTES EM PLANTAS DE GIRASSOL
}

(Helianthus annuus)

Nykolas Carvalho Schiavon ${ }^{1}$, Ramony Cristina Lima ${ }^{2}$, Vinícius Faúla Aguiar ${ }^{3}$, Viktor Kayro Souza Santos ${ }^{3}$, Gustavo Antônio Mendes Pereira ${ }^{4 *}$, Enilson de Barros Silva ${ }^{5}$, Evander Alves Ferreira ${ }^{6}$

\footnotetext{
${ }^{1}$ Graduado em Agronomia, Fertilidade do solo, Universidade Federal dos Vales do Jequitinhonha e Mucuri, Diamantina, Minas Gerais.

${ }^{2}$ Doutoranda em Produção Vegetal, Manejo e conservação de solos, Universidade Federal dos Vales do Jequitinhonha e Mucuri, Diamantina, Minas Gerais.

${ }^{3}$ Mestrando em Produção Vegetal, Fertilidade do Solo, Universidade Federal dos Vales do Jequitinhonha e Mucuri, Diamantina, Minas Gerais.

4 Pós-doutorado, Matologia, Universidade Federal de Viçosa, Viçosa, Minas Gerais. *E-mail: gustavogamp@hotmail.com.

${ }^{5}$ Professor de Fertilidade do solo, Universidade Federal dos Vales do Jequitinhonha e Mucuri, Diamantina, Minas Gerais.

${ }^{6}$ Pós-doutorado, Matologia, Universidade Federal dos Vales do Jequitinhonha e Mucuri, Diamantina, Minas Gerais.
}

RESUMO: A composição química e o acúmulo de nutrientes em folhas e frutos do girassol são informações imprescindíveis para se conhecer as exigências nutricionais da espécie. Posteriormente, essas informações podem servir de subsídio para estimar a quantidade dos nutrientes a ser fornecida às plantas por meio da adubação. Dessa forma, objetivou-se com o presente estudo conhecer o acúmulo de macro e micronutrientes nos tecidos vegetais da cultura do girassol, bem como, identificar em que fases o requerimento de nutrientes é mais crítica. Um experimento foi realizado, em Diamantina-MG, no delineamento experimental em blocos ao acaso, com 4 repetições. $\mathrm{O}$ delineamento experimental utilizado foi em blocos ao acaso, com 8 tratamentos e 4 repetições. Cada tratamento correspondeu a uma época de amostragem, realizadas de 10 em 10 dias após a semeadura, até o final do ciclo da cultura, aos 80 dias. Foram avaliados o acúmulo de macro e micronutrientes pela planta de girassol em cada época. Os macronutrientes mais acumulados na planta como um todo foram $\mathrm{N}>\mathrm{K}$ $>\mathrm{S}>\mathrm{Ca}>\mathrm{Mg}>\mathrm{P}$, bem como, foi encontrada a seguinte ordem de acúmulo para os micronutrientes $\mathrm{Fe}>\mathrm{Zn}>\mathrm{Cu}>\mathrm{Mn}$. A maior taxa de crescimento da cultura foi aos 30 DAE, período este, coincidente com o início do estádio reprodutivo das plantas de girassol. Maiores taxas de absorção de $\mathrm{N}$ e K em toda a planta ocorreram no final da fase vegetativa para o início da fase reprodutiva e o maior pico de absorção de $\mathrm{P}$ foi verificado entre 40 e 50 DAE em plena fase de formação dos frutos.

Palavras-chave: Análise de crescimento. Taxa de absorção de nutrientes. Taxa de crescimento relativa. Helianthus annuus. 


\section{NUTRIENT UPTAKE IN SUNFLOWER (Helianthus annuus) PLANTS}

ABSTRACT: The chemical composition and the accumulation of nutrients in leaves and fruits are essential information to meet the nutritional requirements of the sunflower crop. Later, this information can serve as input to estimate the amount of nutrients to be supplied to the plants through fertilization. Thus, the aim with this study was to evaluate the macro and micronutrient accumulation in plant tissues of sunflower crop, as well as identify doing critical nutrient uptake by the crop. An experiment was conducted in Diamantina-MG, the experimental design of randomized blocks, with four repetitions. The treatments consisted of sampling time, held from 10 to 10 days after planting the species, until the end of the crop cycle, at 80 days. They evaluated the accumulation of macro and micronutrients by sunflower plant each season. The most accumulated macronutrients were $\mathrm{N}>\mathrm{K}>\mathrm{S}>\mathrm{Ca}>$ $\mathrm{Mg}>\mathrm{P}$, as well as the accumulation following order was found for micronutrients $\mathrm{Fe}>\mathrm{Zn}$ $>\mathrm{Cu}>\mathrm{Mn}$. Most crop growth rate was at $30 \mathrm{DAE}$, this period coincides with the beginning of the reproductive stage of sunflower plants. Further $\mathrm{N}$ and $\mathrm{K}$ absorption rates occurred at the end of the vegetative phase to the beginning of the reproductive stage and the largest absorption peak $\mathrm{P}$ was observed between 40 and $50 \mathrm{DAE}$ in full fruit formation stage.

Key words: Analysis of growth. Nutrient absorption rate. Relative growth rate. Helianthus annuus.

\section{INTRODUÇÃO}

O girassol (Helianthus annuus L.) é uma eudicotiledônea anual originária da América do Norte. É uma planta que se adapta bem a diversas condições edafoclimáticas, caracterizando-se pela tolerância a baixas temperaturas na fase inicial de desenvolvimento e pela relativa resistência a déficits hídricos. Pode ser cultivada em todas as regiões do Brasil, pois o rendimento é pouco influenciado pelas latitudes e altitudes, assim como pelo fotoperíodo, o que facilita a expansão do cultivo no país (CASTRO; FARIAS, 2005; ZOBIOLE et al., 2010).

Existem duas fases de crescimento e desenvolvimento da planta de girassol, vegetativa e reprodutiva. A vegetativa engloba desde o período da germinação até o período do broto floral, sendo dividida em Ve (emergência) e Vi (aparecimento de folhas verdadeiras) que é definido pelo número de folhas com no mínimo $4 \mathrm{~cm}$ de comprimento (V1, V2, V3, V4 e Vn). Já a fase reprodutiva, é dividida em: R1 -inflorescência circundada pela bráctea imatura torna-se visível; R2 e R3 - elongação do internódio imediatamente abaixo da base da inflorescência; R4 e R5 - abertura da inflorescência e início da antese, respectivamente; R6 - a antese está completa e as flores liguladas perdem a turgidez; R7 e R8 - enchimento de aquênios; e R9 - maturação fisiológica (CASTRO; FARIAS, 2005 citado por ZOBIOLE et al., 2010). 
Para o estudo adequado dos períodos de adubação de uma cultura, o primeiro passo é conhecer os estádios de desenvolvimento onde a cultura possua maiores exigências nutricionais. De acordo com Nascimento et al., (2012), o melhor manejo da adubação consistiria na aplicação dos nutrientes exigidos no momento exatamente anterior as etapas do desenvolvimento da planta onde se mensuram elevadas taxas de requisição daqueles. $\mathrm{O}$ estabelecimento desses dados e valores se dá pelo estudo chamado de "marcha de absorção", pesquisas pelas quais se pretendem estabelecer as quantidades absorvidas de nutrientes em função da idade e/ou estádio fisiológico de uma cultura (ECHER et al., 2009). Assim a determinação da absorção e da acumulação de nutrientes nas diferentes fases de desenvolvimento da planta é importante, porque permite identificar as épocas em que os elementos são mais exigidos durante o desenvolvimento da cultura e a sua distribuição nas diferentes estruturas da planta possibilitando um manejo adequado da adubação.

Também deve ser levada em consideração a eficiência de aproveitamento dos adubos aplicados e a fração de nutrientes que fica retida no solo e não é disponibilizada para as plantas (LAVIOLA et al., 2008; ROSOLEM et al., 2012). As composições químicas em folhas e frutos tanto quanto o acúmulo de nutrientes são informações imprescindíveis para conhecer as exigências nutricionais de uma espécie. Posteriormente, essas informações podem servir como subsídio para estimar a quantidade dos nutrientes a ser fornecida às plantas por meio da adubação.

Assim, objetivou-se com o presente estudo conhecer a relação de acúmulo de macro e micronutrientes nos tecidos vegetais da cultura do girassol, bem como, identificar em que fases o requerimento de nutrientes é mais crítica.

\section{MATERIAL E MÉTODOS}

O experimento foi realizado em condições de campo, no período de dezembro de 2009 a maio de 2010, no Setor de Horticultura do Departamento de Ciências Agrárias da Universidade Federal dos Vales do Jequitinhonha e Mucuri (UFVJM), no município de Diamantina, MG, situada a $18^{\circ} 10^{\prime} \mathrm{S}$ e $43^{\circ} 30^{\prime} \mathrm{O}$ e a 1250 metros de altitude. O clima local é do tipo Cwb (temperado, com inverno seco), segundo a classificação de Köppen. Os dados meteorológicos obtidos na estação meteorológica do INMET, em Diamantina, MG, referentes ao período do experimento são: temperatura máxima $\left(26,6^{\circ} \mathrm{C}\right)$, média $\left(21,7^{\circ} \mathrm{C}\right)$ e mínima $\left(16,7^{\circ} \mathrm{C}\right)$; precipitação média $(0,0 \mathrm{~mm})$.

O solo da área experimental foi classificado como Neossolo Quartzarênico Órtico típico (RQo) (classificação do solo SiBCS), textura arenosa e declividade de 2\%. A análise química do solo apresentou o seguinte resultado: $\mathrm{pH}$ (água) de 5,4; teor de matéria orgânica de $1 \mathrm{daq}^{-1}$; $\mathrm{P}, \mathrm{K}$ e Ca de 1,4; 10 e 0,5 mg dm${ }^{-3}$, respectivamente; $\mathrm{Mg}, \mathrm{Al}, \mathrm{H}+\mathrm{Al}$ e CTC efetiva de 0,$2 ; 0,4 ; 4,4$ e $1,7 \mathrm{cmol}_{\mathrm{c}} \mathrm{dm}^{-3}$, respectivamente, segundo a metodologia da Empresa Brasileira de Pesquisa Agropecuária - EMBRAPA (1997). 
A área experimental foi inicialmente corrigida com a incorporação de $2 \mathrm{t} \mathrm{ha}^{-1}$ de calcário dolomítico $(\mathrm{CaO}=48 \% ; \mathrm{MgO}=10 \%$; $\mathrm{PRNT}=85 \%)$. A adubação de semeadura foi realizada aplicando-se [sulfato de amônio $\left(95 \mathrm{~kg} \mathrm{ha}^{-1}\right)$, superfosfato simples (389 $\left.\mathrm{kg} \mathrm{ha}^{-1}\right)$ e cloreto de potássio ( $83 \mathrm{~kg} \mathrm{ha}^{-1}$ ) no sulco de semeadura e de cobertura aos 50 dias após a emergência com aplicação de sulfato de amônio $\left(190 \mathrm{~kg} \mathrm{ha}^{-1}\right)$, conforme recomendação para a cultura do girassol no estado de Minas Gerais (RIBEIRO; GUIMARÃES; ALVAREZ V., 1999).

A semeadura do girassol (cv. Charrua) seguiu o espaçamento 1,0 x 0,20 m $(50.000$ plantas ha-1), de acordo com as recomendações para esta cultura no estado de Minas Gerais (RIBEIRO; GUIMARÃES; ALVAREZ V., 1999). As densidades de plantas almejadas foram mantidas por meio de desbastes.

O delineamento experimental utilizado foi em blocos ao acaso, com 8 tratamentos e 4 repetições, totalizando 32 parcelas experimentais. Cada tratamento correspondeu a uma época de amostragem, realizadas de 10 em 10 dias após a semeadura, até o final do ciclo da cultura, aos 80 dias. A parcela experimental foi constituída de $4 \mathrm{~m}$ lineares, espaçadas em 1,0 m (RIBEIRO; GUIMARÃES; ALVAREZ V., 1999). A coleta de acordo com cada variável analisada, sempre foi realizada nos 2 metros centrais da segunda e terceira linhas, deixando-se duas linhas laterais para efeito de bordadura.

Após estas coletas, as plantas foram separadas em caule e folhas e todo o material vegetal foi lavado em água destilada e seco em estufa com circulação forçada de ar, a $65^{\circ} \mathrm{C}$, até atingir peso constante para determinação da massa da matéria seca da parte aérea. $\mathrm{O}$ material seco foi triturado em moinho equipado com peneira fina (40 mesh), visando homogeneização do material. Em seguida determinaram-se os teores de macro e micronutrientes (MALAVOLTA et al., 1997).

Com a massa de matéria seca e teor de nutrientes calculou-se o acúmulo nas folhas e no caule das plantas de girassol. Calculado pela seguinte equação:

\section{$\mathrm{A}=$ massa seca $\mathrm{x}$ teor de nutriente}

Também foi determinado o acúmulo de massa da matéria seca nas folhas, caule, frutos e sementes da cultura durante o ciclo de avaliação, bem como, a taxa de crescimento relativo da cultura de acordo com a Equação 1 e a taxa de absorção de nitrogênio, fósforo e potássio de acordo com a Equação 2 (BENINCASA, 2003).

Equação 1. Taxa de crescimento (TC), representa a produção de massa da matéria seca total em cada período de tempo.

$$
\mathrm{TCR}=\frac{\mathrm{P} 2-\mathrm{P} 1}{\mathrm{~T} 2-\mathrm{T} 1}
$$

P1 e P2: massa da matéria seca total (MST) de duas amostragens sucessivas.

$\mathrm{T} 1$ e T2: intervalo de tempo em dias entre as duas amostragens. 
Equação 2. Taxa de absorção de N, P e K. (TA), mesma interpretação pode ser dada para a taxa de absorção que representa a absorção de determinado nutriente num dado período de tempo.

$\mathrm{TA}=\frac{\mathrm{TR} 1-\mathrm{T} 1}{\mathrm{TR} 2-\mathrm{T} 2}$

TR1 e TR2: teores de nutrientes de duas amostragens sucessivas.

T1 e T2: intervalo de tempo em dias entre as duas amostragens.

Os dados foram submetidos a análise de variância e apresentados na forma descritiva, utilizando os softwares Sisvar® 5.6 e Microsoft ${ }^{\circledR}$ Excel® ${ }^{\circledR}$ 2016. O acúmulo de nutrientes e de massa da matéria seca foram apresentados na forma de gráficos que representam a distribuição em cada parte da planta. A taxa de crescimento das plantas e a de absorção de macronutrientes foram representadas por linhas de tendência. $\mathrm{O}$ acúmulo de macro e micronutrientes ao final do ciclo da cultura foram representados por gráficos de barras.

\section{RESULTADOS E DISCUSSÃO}

Ao avaliar o acúmulo de micronutrientes nas folhas e no caule de plantas de girassol, constatou-se que o cobre $(\mathrm{Cu})$, até os 30 dias após a emergência (DAE) se acumulou em maior quantidade no caule com pequena diferença em relação as folhas, sendo que, dessa data em diante esse micronutriente acumulou em maior proporção no caule em relação as folhas (Figura 1A). O acúmulo deste micronutriente foi crescente durante todo o ciclo da cultura.

Resultados semelhantes foram encontraram para o acúmulo de cobre por Sfredo e Sarruge (1990). Os autores relataram que, para folhas e caules, o acúmulo mais intenso deste micronutriente também se deu a partir dos 28 dias após a emergência, atingindo um máximo aos 80 dias.

O acúmulo de manganês $(\mathrm{Mn})$ e zinco $(\mathrm{Zn})$ foi maior no caule até aproximadamente 60 DAE, sendo que, a partir dessa avaliação esses micronutrientes se acumularam em maior proporção nas folhas (Figura $1 \mathrm{~B})$. O ferro $(\mathrm{Fe})$ teve incremento no caule com o tempo em relação às folhas, destacando-se que, no final do ciclo foram observadas três vezes mais $\mathrm{Fe}$ no caule em comparação com as folhas (Figura 1D).

Maior acúmulo de boro (B) foi constatado nas folhas de girassol em relação ao caule aproximadamente até os 60 DAE. Entretanto, a partir dessa época as folhas apresentaram maior acúmulo de B até o final do ciclo de avaliação da cultura (Figura 1E).

Sfredo e Sarruge (1990) observaram que o nas plantas de girassol, houve a mesma tendência para o manganês nas folhas e caules, diferente dos resultados observados no presente trabalho. Já para o Zn, a observação foi semelhante ao ocorrido no presente estudo. Os autores também observaram que o B diferente do constatado nesse estudo, acumulou-se durante todo o ciclo do girassol, nos caules. Existem vários estudos que relatam a 
deficiência de plantas de girassol a este nutriente, apesar de pouca exigência da cultura (BONACIN et al., 2009; LIMA et al., 2013; PRADO e LEAL, 2006). Por isso, os autores alertam que os cuidados com a adubação com este elemento devem ser maiores. Castro et al. (2006) relatam que a absorção de B é facilitada quando o suprimento hídrico é adequado para as plantas.

A

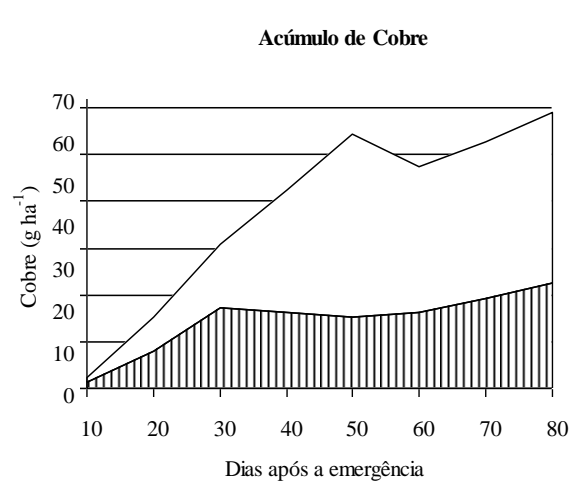

$\mathrm{C}$

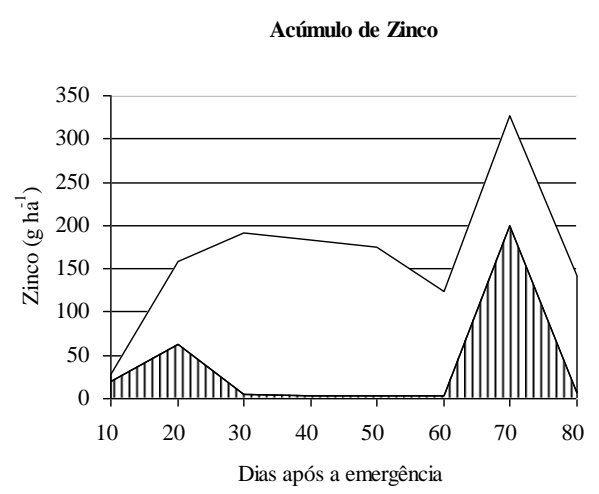

B
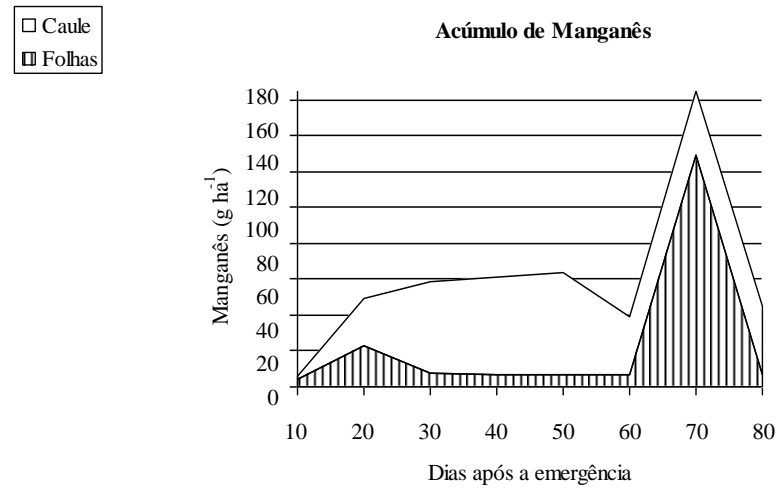

$\mathrm{D}$

$\square$ Caule $\square$ Folhas

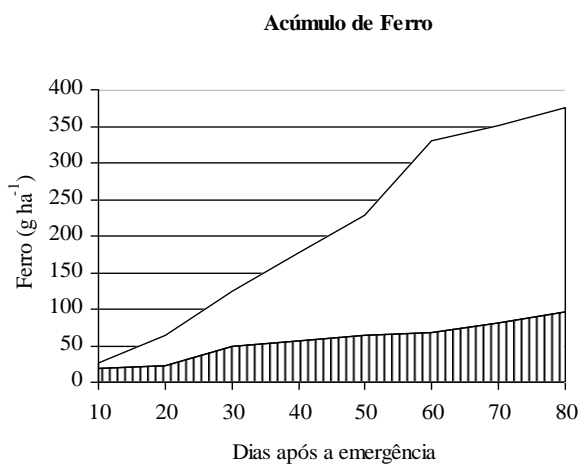

$\mathrm{E}$

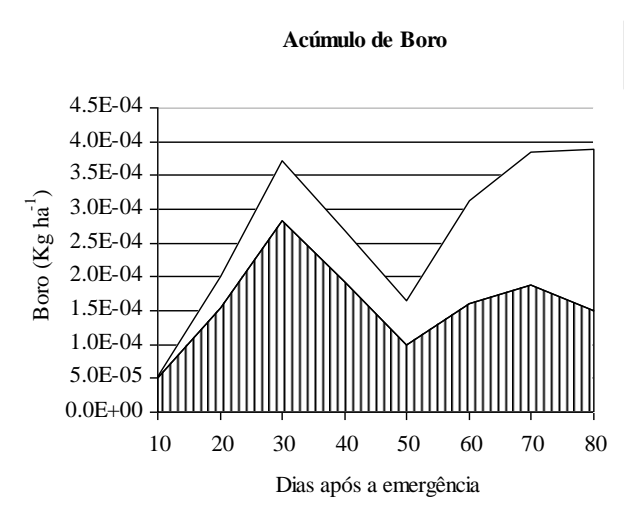

Figura 1. Micronutrientes em folhas e caule de plantas de girassol em diferentes épocas de avaliação. A) cobre; B) manganês; C) zinco; D) ferro; E) boro.

Cultura Agronômica, Ilha Solteira, v.27, n.2, p.236-250, 2018 
Plantas de girassol se comportaram de maneira diferenciada com relação ao acúmulo de macronutrientes. $\mathrm{O}$ nitrogênio $(\mathrm{N})$ apresentou tendência de se acumular em maior proporção nas folhas em relação ao caule, considerando também que ocorreu incremento da concentração desse nutriente durante o ciclo de avaliação da cultura (Figura 2A).

A

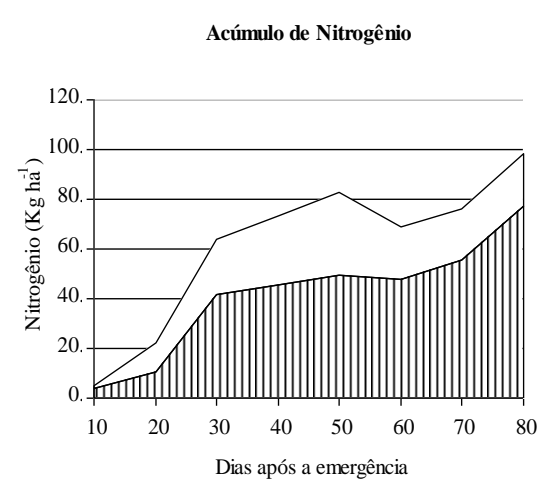

$\mathrm{C}$

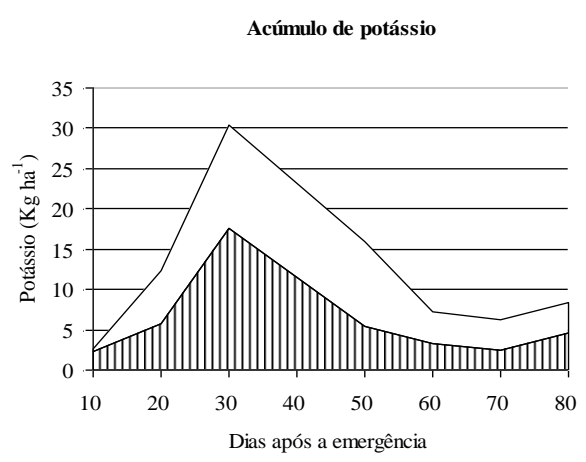

E

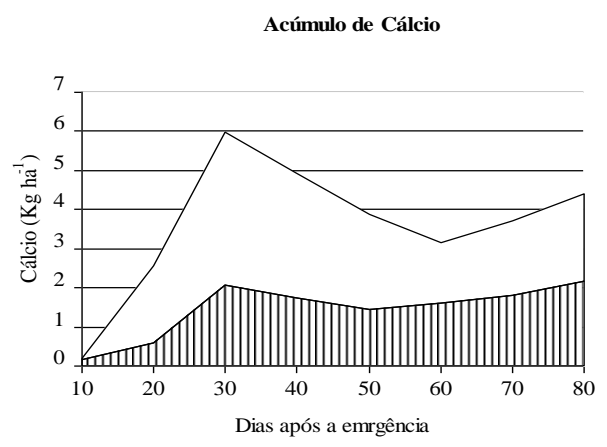

B

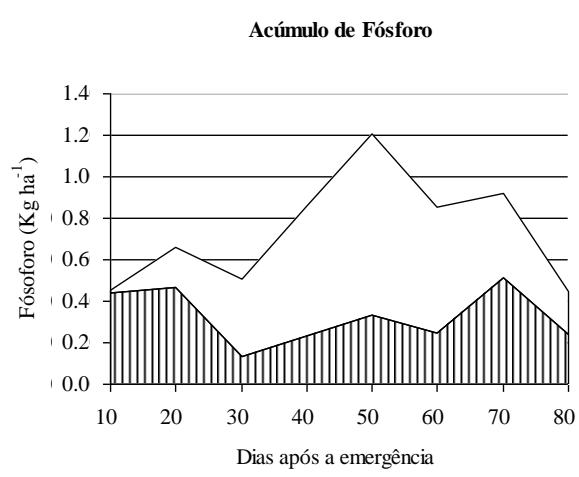

$\mathrm{D}$ $\square$ Caule

m Folhas

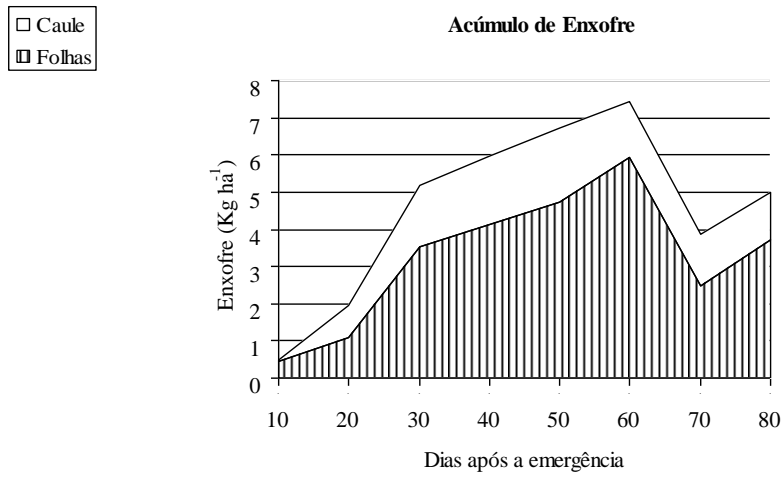

$\mathrm{F}$

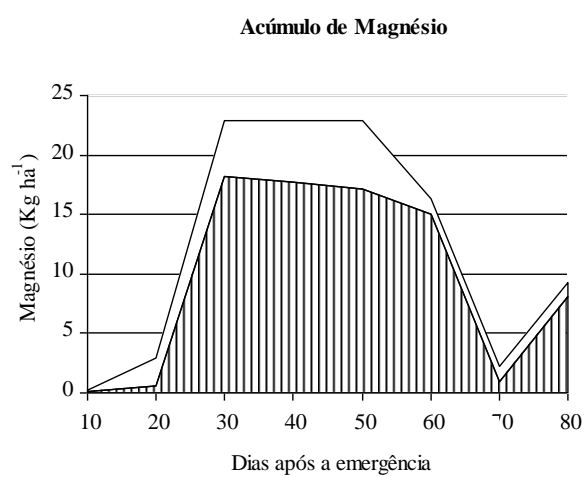

Caule ㅁ Folhas $\square$ Caule 凹 Folhas Dias após a emergência

Figura 2. Macronutrientes em folhas e caule de plantas de girassol em diferentes épocas de avaliação. A) nitrogênio; B) fósforo; C) potássio; D) enxofre; E) cálcio; F) magnésio. 
O fósforo (P) apresentou-se em maior proporção nas folhas de girassol até aproximadamente 20 DAE. No entanto, a partir dessa época de avaliação esse nutriente mostrou maior tendência de acúmulo no caule até 70 DAE. A partir desse período de avaliação observou-se redução do acumulo de $\mathrm{P}$ em ambos os órgãos avaliados, provavelmente devido à translocação de $\mathrm{P}$ para a formação do fruto e enchimento dos grãos (Figura 2B).

O maior acúmulo de $\mathrm{N}$ e $\mathrm{P}$ nas folhas na fase inicial também foi observado por Sfredo et al. (1984) e Zobiole et al. (2010). Os autores também observaram que a partir dos 28 DAE, a taxa de acúmulo de $\mathrm{N}$ e $\mathrm{P}$ aumentou de forma acentuada. A maior taxa de absorção de $\mathrm{N}$ coincide com a mudança de estádio de desenvolvimento da cultura, vegetativo para reprodutivo que ocorreu aproximadamente aos 25 DAE. Prado e Leal (2006) observaram que a omissão de $\mathrm{P}$, conjuntamente com o $\mathrm{N}$, foi a condição que mais reduziu o crescimento das folhas e do caule. Esta interação entre os nutrientes pode estar relacionada com a participação do ATP na assimilação de N (ARAÚJO; MACHADO, 2006).

Com relação ao potássio $(\mathrm{K})$, verificou-se um pico de acúmulo desse nutriente aos 30 DAE, tanto nas folhas como no caule, seguido de uma queda constante até aproximadamente 60 dias, sendo que, a partir desse momento houve estabilização na concentração de $\mathrm{K}$ até a última avaliação, nesse caso, deve-se considerar também a translocação de $\mathrm{K}$, das folhas e caule para os órgãos reprodutivos. Destacando-se também que o $\mathrm{K}$ se acumulou em maior proporção no caule em relação às folhas (Figura 2C).

Sfredo et al. (1984) e Zobiole et al. (2010), também observaram que o K não segue o mesmo padrão verificado para $\mathrm{N}$ e para o $\mathrm{P}$, pois, durante as fases vegetativas e também durante o início da fase reprodutiva (estádio R1), aproximadamente 50 a $60 \%$ do K estava alocado nos caules e não nas folhas. Nesse sentido, Putt (1997) relatou que, devido a esse alto acúmulo de $\mathrm{K}$ no caule do girassol, a Rússia, no início do século XX, produziu e exportou K utilizando caule de girassol como fonte de nutriente. Uchoa et al. (2011) e Salvador et al. (2011) alertam que aplicações excessivas de cloreto de potássio podem inibir a absorção de $\mathrm{Ca}^{2+}$ e $\mathrm{Mg}^{2+}$ tal como a diminuição de $\mathrm{P}$.

O enxofre teve acúmulo crescente tanto nas folhas quanto no caule de girassol até cerca de 60 DAE, destacando-se que o mesmo se encontrou em maior proporção nas folhas durante esse período (Figura 2D). A partir dessa época constatou-se queda nos valores de acúmulo de $\mathrm{S}$ em ambos os órgãos vegetais avaliados até 70 DAE com leve acréscimo posterior a esse período tanto nas folhas quanto no caule.

Observou-se aumento do acúmulo de cálcio (Ca) nos órgãos das plantas de girassol até aproximadamente 30 DAE, seguido de decréscimo até aos 60 DAE (Figura 2E). A partir dessa avaliação foi observado leve acréscimo na concentração desse nutriente tanto nas folhas quanto no caule, destacando-se também que o Ca se encontrou em maior proporção durante as épocas de avaliação principalmente no caule.

Cultura Agronômica, Ilha Solteira, v.27, n.2, p.236-250, 2018 
Sfredo et al. (1984) também verificaram aumento acentuado no acúmulo de cálcio nas plantas a partir dos 42 dias. Todavia, estes autores observaram maiores acúmulos de Ca nas folhas ao invés de no caule, havendo decréscimo no acúmulo de Ca até o final do ciclo devido, principalmente, a queda das folhas a partir da maturação fisiológica. Prado e Leal (2006) relatam que a omissão do Ca pode ocasionar diminuição do número de folhas, altura da planta, diâmetro do capítulo e da área foliar.

Com relação ao magnésio $(\mathrm{Mg})$, observou-se intenso acúmulo desse nutriente tanto nas folhas como no caule até cerca de 30 DAE, sendo que, a curva se estabilizou até aproximadamente aos $50 \mathrm{DAE}$, seguido de uma queda acentuada na concentração de $\mathrm{Mg}$ até 70 DAE, com leve incremento posterior a esta dada. $\mathrm{O} \mathrm{Mg}$ se acumulou em maior quantidade nas folhas de girassol em praticamente todos os períodos de avaliação (Figura 2F). A queda do acúmulo de $\mathrm{Mg}$ a partir dos 50 DAE se deve a redistribuição desse elemento na fase reprodutiva para estruturas de reprodução (ZOBIOLE et al., 2010).

Constatou-se acréscimo no acúmulo de massa da matéria seca total de plantas de girassol até aproximadamente 60 DAE, seguido de uma leve redução nos valores dessa variável até o final do ciclo de avaliação (Figura 3). Entre os 20 e 30 DAE iniciou-se o acúmulo de massa da matéria seca nos frutos até aproximadamente $60 \mathrm{DAE}$, sendo que, o acúmulo de massa da matéria seca nos grãos se iniciou aos 40 DAE com o máximo aos 80 DAE.

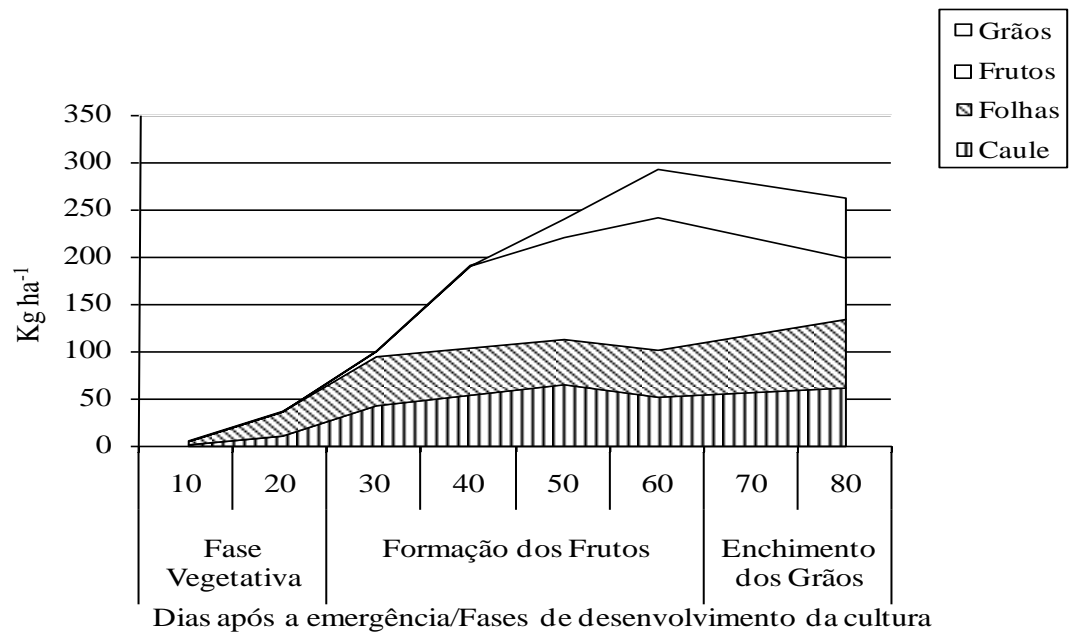

Figura 3. Massa da matéria seca de folhas, caule, frutos e sementes de plantas de girassol em diferentes épocas de avaliação.

Assim o girassol apresentou na fase vegetativa maior proporção de massa matéria seca nas folhas. No entanto, na fase reprodutiva maior proporção do crescimento em massa da matéria seca foi destinada aos órgãos reprodutivos com maior crescimento dos frutos e grãos (Figura 3). Verificou-se, portanto, que o acúmulo de matéria seca foi representado em maior massa pelas estruturas reprodutivas (frutos e sementes), seguido pelo caule e por último pelas folhas (Estruturas reprodutivas > Folhas $>$ Caule).

Cultura Agronômica, Ilha Solteira, v.27, n.2, p.236-250, 2018 
De modo geral, o máximo acúmulo diário dos nutrientes coincidiu com o período inicial de frutificação (Figura 4), do girassol, como também observado por Bianco et al. (2012) e Carvalho et al. (2014) em outras culturas. Com o início da frutificação ocorre um aumento dos nutrientes e assimilados, devido ao aumento da atividade metabólica, associada à atividade hormonal e a divisão e crescimento celular (TAIZ; ZEIGER, 2013). A absorção de nutrientes é diferente de acordo com a fase de desenvolvimento da cultura, intensificando-se no florescimento, na formação e no crescimento dos frutos ou do órgão que será colhido, por isso, além da quantidade absorvida de nutrientes, deve ser considerada também, a sua concentração nos diferentes estádios de desenvolvimento (MALAVOLTA et al., 1997).

Taxa de Crescimento

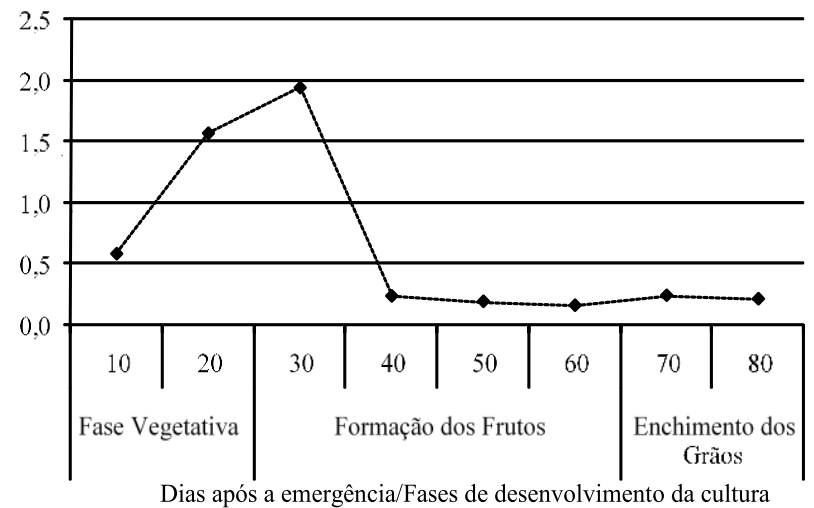

Figura 4. Taxa de crescimento de plantas de girassol em diferentes épocas de avaliação.

Ao avaliar a taxa de crescimento das plantas de girassol durante as épocas de avaliação, observou-se elevado incremento dessa variável até 30 DAE, seguida do decréscimo da mesma até 40 DAE. A partir desse período a taxa de crescimento apresentouse estável até o final do ciclo de avaliação da cultura (Figura 4).

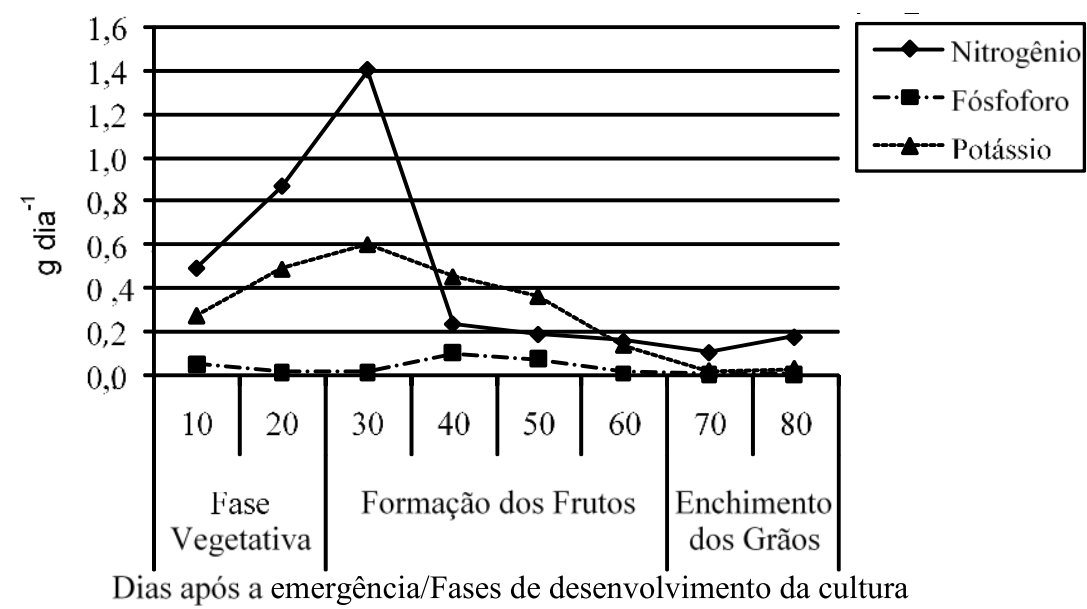

Figura 5. Taxa de absorção de nitrogênio, fósforo e potássio em plantas de girassol em diferentes épocas de avaliação.

Cultura Agronômica, Ilha Solteira, v.27, n.2, p.236-250, 2018 
A taxa de absorção de $\mathrm{N}$ nas plantas de girassol atingiu o pico aos $30 \mathrm{DAE}$, seguida de uma redução drástica até aos 40 DAE. A partir dos 40 DAE constatou-se uma redução lenta e gradual até o final do ciclo de avaliação (Figura 5).

Semelhante ao observado para o $\mathrm{N}$, as plantas de girassol tiveram acréscimo na taxa de absorção de $\mathrm{K}$ até aos $30 \mathrm{DAE}$, no entanto, as taxas de absorção de $\mathrm{K}$ foram menores do que as observadas para o N. A partir dos 30 DAE a taxa de absorção de K foi decaindo lenta e gradualmente até aos 80 DAE (Figura 5).

Já a taxa de absorção de $\mathrm{P}$, foi a menor durante o ciclo de avaliação comparada ao $\mathrm{N}$ e ao K. Maior taxa de absorção de $\mathrm{P}$ foi observada entre 40 e 50 DAE, já na fase de formação dos frutos (Figura 5).

Ao avaliar o acúmulo de macronutrientes na parte aérea aos 80 DAE, constatou-se a seguinte ordem decrescente: $\mathrm{N}>\mathrm{K}>\mathrm{S}>\mathrm{Ca}>\mathrm{Mg}>\mathrm{P}$ (Figura 6A). Já com relação aos micronutrientes foi observada a seguinte ordem: $\mathrm{Fe}>\mathrm{Zn}>\mathrm{Cu}>\mathrm{Mn}$ (Figura 6B).

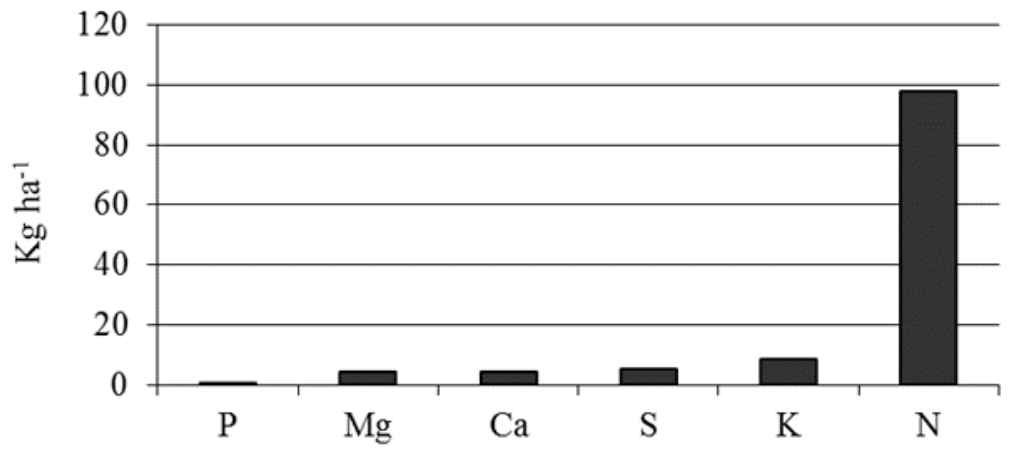

Nutrientes

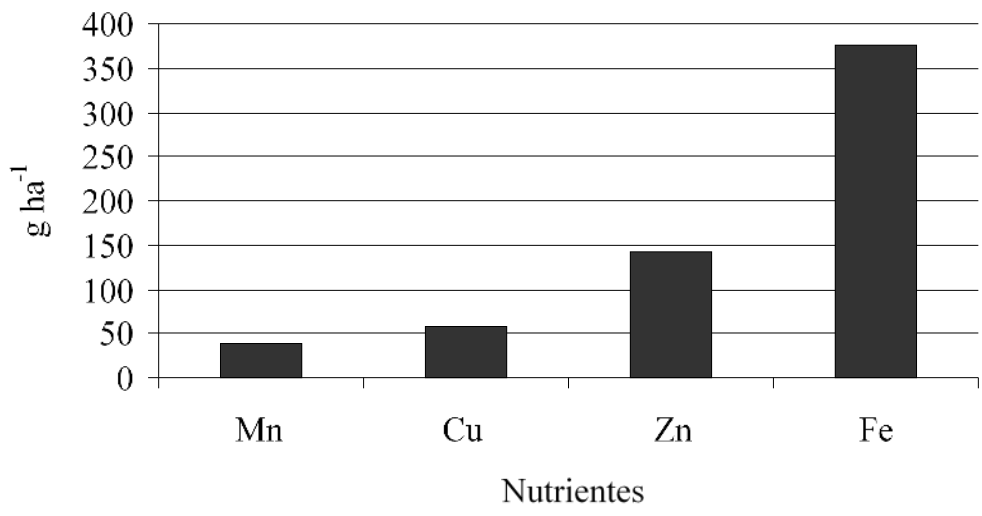

B

Figura 6. A) Macronutrientes $\mathrm{N}, \mathrm{P}, \mathrm{K}, \mathrm{S}, \mathrm{Ca}$ e $\mathrm{Mg}$ e B) Micronutrientes $\mathrm{Fe}, \mathrm{Zn}, \mathrm{Cu}$ e $\mathrm{Mn}$ em plantas de girassol aos 80 dias após a emergência (DAE) da cultura.

Zobiole et al. (2010) encontraram a seguinte ordem de extração de macronutrientes pelas plantas de girassol: $\mathrm{K}>\mathrm{N}>\mathrm{Ca}>\mathrm{Mg}>\mathrm{P}=\mathrm{S}$, diferindo do encontrado no presente trabalho. Segundo Aquino et al. (2013), os teores foliares de N, K e Ca não são influenciados pelas cultivares de girassol, o que indica que está variação pode estar relacionada com os teores dos nutrientes presentes nos solos.

Cultura Agronômica, Ilha Solteira, v.27, n.2, p.236-250, 2018 
Aquino et al. (2013), Sfredo e Sarruge (1990) e Zobiole et al., (2011) trabalhando com acúmulo de micronutrientes na cultura do girassol encontraram a seguinte ordem de acumulação: $\mathrm{Mn}>\mathrm{B}>\mathrm{Fe}>\mathrm{Zn}>\mathrm{Cu}$; $\mathrm{Fe}>\mathrm{Mn}>\mathrm{Zn}>\mathrm{B}>\mathrm{Cu}$ e; $\mathrm{Fe}>\mathrm{Mn}>\mathrm{B}>\mathrm{Zn}>\mathrm{Cu}$, respectivamente, também indicando que o acúmulo de micronutrientes na cultura do girassol pode variar de acordo com suas concentrações no solo (DECHEN; NACHTIGALL, 2005).

\section{CONCLUSÃO}

1 - As plantas de girassol acumularam macronutrientes na seguinte ordem de magnitude: $\mathrm{N}>\mathrm{K}>\mathrm{S}>\mathrm{Ca}>\mathrm{Mg}>\mathrm{P}$ e micronutrientes na ordem: $\mathrm{Fe}>\mathrm{Zn}>\mathrm{Cu}>\mathrm{Mn}$.

2 - A maior taxa de crescimento do girassol foi aos 30 dias após a germinação.

3 - As maiores taxas de absorção de nitrogênio e potássio ocorreram entre o final da fase vegetativa e início da fase reprodutiva.

4 - A maior taxa de absorção de fósforo foi verificada entre 40 e 50 dias após a emergência, período correspondente à formação dos frutos.

\section{AGRADECIMENTOS}

Os autores agradecem a Coordenação de Aperfeiçoamento e Pessoal de Nível Superior (CAPES) e a Fundação de Amparo à Pesquisa do Estado de Minas Gerais (FAPEMIG) pelo apoio financeiro e pelas bolsas concedidas.

\section{REFERÊNCIAS BIBLIOGRÁFICAS}

AQUINO, L. A.; SILVA, F. D. B.; BERGER, P. G. Características agronômicas e o estado nutricional de cultivares de girassol irrigado. Revista Brasileira de Engenharia Agrícola e Ambiental, Campina Grande, v. 17, n. 5, p.551-557, 2013. Disponível em: <http://www.scielo.br/pdf/rbeaa/v17n5/a13v17n5.pdf>. Acesso em: 10 jan. 2017.

ARAÚJO, A. P.; MACHADO, C. T. T. Fósforo. In: Nutrição mineral de plantas. FERNANDES, M. S. 1.ed. Viçosa: Sociedade Brasileira de Ciência do Solo, 2006. cap 10, p.253-280.

BENINCASA, M. M. P. Análise de crescimento de plantas: noções básicas. 2 ed. Jaboticabal: FUNEP, 2003. 42 p.

BIANCO, S. I.; CARVALHO, L. B.; BIANCO, M. S.; PITELLI, R. A. Acúmulo de massa seca e de macronutrientes por plantas de Glycine max e Solanum americanum. Planta daninha, Viçosa, v. 30, n. 1, p.87-95, 2012. Disponível em: <http://www.scielo.br/scielo.php?script=sci_arttext\&pid=S0100-83582012000100010>. Acesso em: 15 nov. 2016. 
BOnACIN, G. A.; RODRIGUES, T. J. D.; CRUZ, M. C. P.; BANZATTO, D. A. Características morfofisiológicas de sementes e produção de girassol em função de boro no solo. Revista Brasileira de Engenharia Agrícola e Ambiental, Campina Grande, v. 13, n. 2, p.111-116, 2009. Disponível em: <http://www.scielo.br/scielo.php?script=sci_arttext\&pid=S1415-43662009000200001>. Acesso em: 20 dez. 2016.

CARVALHO, L. B.; BIANCO, S.; BIANCO, M. S. Estudo comparativo do acúmulo de massa seca e macronutrientes por plantas de Zea mays e Ipomoea hederifolia. Planta daninha, Viçosa, v. 32, n. 1, p.99-107, 2014. Disponível em: <http://www.scielo.br/scielo.php?script=sci_arttext\&pid=S0100-83582014000100011>. Acesso em: 20 nov. 2016.

CASTRO, C.; MOREIRA, A.; OLIVEIRA, R. F.; DECHEN, A. R. Boro e estresse hídrico na produção do girassol. Ciência e Agrotecnologia, Lavras, v. 30, n. 2, p.214-220, 2006. Disponível em: <http://www.scielo.br/scielo.php?script=sci_arttext\&pid=S141370542006000200004>. Acesso em: 05 jun. 2016.

RIBEIRO, A. C.; GUIMARÃES, P. T. G.; ALVAREZ V., V. H. (Eds.). Recomendações para o uso de corretivos e fertilizantes em Minas Gerais. 5.ed. Viçosa: COMISSÃO DE FERTILIDADE DO SOLO DO ESTADO DE MINAS GERAIS - CFSEMG / UFV, 1999. $359 \mathrm{p}$.

DECHEN, A. R.; NACHTIGALL, G. R. Micronutrientes. In: Nutrição mineral de plantas. FERNANDES, M. S. (ed.) 1.ed. Viçosa: Sociedade Brasileira de Ciência do Solo, 2006. cap. 13, p. $253-280$.

ECHER, F. R.; DOMINATO, J. C.; CRESTE, J. E. Absorção de nutrientes e distribuição da massa fresca e seca entre órgãos de batata-doce. Horticultura Brasileira, Brasília, v. 27, n. 2, p.176-182, 2009. Disponível em: <http://www.scielo.br/pdf/hb/v27n2/v27n2a10.pdf>. Acesso em: 05 jun. 2016.

EMPRESA BRASILEIRA DE PESQUISA AGROPECUÁRIA - EMBRAPA. Manual de Métodos de Análise de Solo. 2.ed. Rio de Janeiro: EMBRAPA-CNPS, 1997. 212 p.

LAVIOLA, B. G.; DIAS, L. A. S. Teor e acúmulo de nutrientes em folhas e frutos de pinhão-manso. Revista Brasileira de Ciência do Solo, Viçosa, v. 32, n. 1, p.1969-1975, 2008. Disponível em: <http://www.scielo.br/pdf/rbcs/v32n5/18.pdf>. Acesso em: 05 jun. 2016.

LIMA, A. D.; VIANA, T. V. A.; AZEVEDO, B. M.; MARINHO, A. B.; DUARTE, J. M. L. Adubação borácica na cultura do girassol. Revista Agro@mbiente On-line, Boa Vista, v. 7, n. 3, p.269-276, 2013. Disponível em: <file://C:/Users/gusta/Downloads/1237-6856-1PB.pdf>. Acesso em: 09 de maio de 2018.

MALAVOLTA, E.; VITTI, G. C.; OLIVEIRA, S. A. Avaliação do estado nutricional das plantas: princípios e aplicações. 2.ed. Piracicaba: POTAFOS, 1997. 319 p.

Cultura Agronômica, Ilha Solteira, v.27, n.2, p.236-250, 2018 
NASCIMENTO, M. S.; CRUSCIOL, C. A. C.; FERNANDES, A. M.; ZANOTTO, M. D. Nutrient extraction and exportation by castor bean hybrid lyra. Revista Brasileira Ciência do Solo, Viçosa, v. 36, n. 1, p.113-124, 2012. Disponível em: <http://www.scielo.br/scielo.php?script=sci_arttext\&pid=S0100-06832012000100013>. Acesso em: 24 jun. 2016.

PRADO, R. M.; LEAL, R. M. Desordens nutricionais por deficiência em girassol variedade Catissol-01. Pesquisa Agropecuária Tropical, Goiânia, v. 36, n. 1, p.187-193, 2006. Disponível em: <http://www.scielo.br/scielo.php?script=sci_nlinks\&ref=000115\&pid=S1415$4366201300050001300020 \& \operatorname{lng}=\mathrm{pt}>$. Acesso em: 20 nov. 2016.

PUTT, E. D. Early history of sunflower. In: SCHENEITER, A. A. Sunflower technology and production. 1.ed. Madison: America Society of Agronomy, 1997. cap. 2, p. 1-19.

ROSOLEM, C. A.; ECHER, F. R.; LISBOA, I. P.; BARBOSA, T. S. Acúmulo de Nitrogênio, fósforo e potássio pelo Algodoeiro sob irrigação cultivado em sistemas convencional e adensado. Revista Brasileira de Ciência do Solo, Viçosa, v. 36, n. 2, p.457-466, 2012. Disponível em: <http://www.scielo.br/scielo.php?script=sci_arttext\&pid=S0100-06832012000200015>. Acesso em: 20 nov. 2016.

SALVADOR, J. T.; CARVALHO, T. C.; LUCCHESI, L. A. C. Relações cálcio e magnésio presentes no solo e teores foliares de macronutrientes. Revista Acadêmica: Ciências Agrárias e Ambientais, Curitiba, v. 9, n. 1, p.27-32, 2011. Disponível em: <file:///C:/Users/gusta/Downloads/academica-5010.pdf>. Acesso em: 22 nov. 2016.

SFREDO, G. J.; SARRUGE, J. R. Acúmulo de micronutrientes em plantas de girassol. Pesquisa Agropecuária Brasileira, Brasília, n. 1, v. 25, p. 499-503, 1990.

SFREDO, G. J.; SARRUGE, J. R.; HAAG, H. P. Dry matter production by two cultivars on sunflower (Helianthus annuus L.). Anais da Escola Superior de Agricultura Luiz de Queiroz, Piracicaba, v. 41, n. 1, p. 21-36, 1984.

TAIZ, L.; ZEIGER, E. Plant physiology. California: The Benjamin/Cummigs Publishing, 2013. 559 p.

UCHÔA, S. C. P.; IVANOFF, M. E. A.; ALVES, J. M. A.; SMIDERLE, O. J.; SEDIYAMA, T. Adubação de potássio em cobertura nos componentes de produção de cultivares de girassol. Revista Ciência Agronômica, Fortaleza, v. 42, n. 1, p.8-15, 2011.

ZOBIOLE, L. H. S.; CASTRO, C.; OLIVEIRA, F. A.; OLIVEIRA JUNIOR, A. Marcha de absorção de macronutrientes na cultura do girassol. Revista Brasileira de Ciência do Solo, Viçosa, v. 34, n. 2, p.425-433, 2010. Disponível em: <http://www.scielo.br/scielo.php?script=sci_arttext\&pid=S0100-06832010000200016>. Acesso em: 22 nov. 2016.

Cultura Agronômica, Ilha Solteira, v.27, n.2, p.236-250, 2018 
ZOBIOLE, L. H. S.; CASTRO, C.; OLIVEIRA, F. A.; OLIVEIRA JÚNIOR, A.; MOREIRA, A. Sunflower micronutrient uptake curves. Ciência e Agrotecnologia, Lavras, v. 35, n. 2, p.346-353, 2011. Disponível em: <http://www.scielo.br/scielo.php?script=sci_arttext\&pid=S1413-70542011000200016>. Acesso em: 22 nov. 2016. 